\title{
A DIMENSÃO VALORATIVA EM DISCURSOS SOBRE O USO DE CITAÇÕES NA ESCRITA DE TEXTOS CIENTÍFICOS
}

\author{
José Cezinaldo Rocha Bessa* \\ Universidade do Estado do Rio Grande do Norte \\ Departamento de Letras Estrangeiras \\ Pau dos Ferros, RN, Brasil
}

\begin{abstract}
Resumo: Fundamentado na concepção dialógica da linguagem do Círculo de Bakhtin, segundo a qual os valores ideológicos constituem a linguagem humana, e em trabalhos sobre escrita científica, sobretudo em perspectiva enunciativa e discursiva, este texto apresenta um estudo sobre a dimensão valorativa que subjaz ao discurso sobre o uso de citações nas práticas comunicativas da esfera acadêmico-científica. De natureza interpretativa e assumindo uma abordagem qualitativa, o trabalho realiza um exame de manuais de metodologia do trabalho científico e de redação científica que circulam no universo acadêmico e no mercado editorial brasileiro. O estudo feito indica que os discursos materializados nos manuais de metodologia do trabalho científico e de redação científica analisados disseminam valores que colaboram para um quadro de exigências paradoxais, que pode muito mais confundir e desorientar o estudante em formação em pesquisa que contribuir efetivamente para uma prática comunicativa científica criativa, adequada $e$ relevante.
\end{abstract}

Palavras-chave: Texto científico. Jovem pesquisador. Discurso. Citação. Dimensão valorativa.

\section{INTRODUÇÃO}

Característica essencial e marcante na constituição da escrita acadêmico-científica, o fenômeno da citação tem sido objeto de estudos de um número considerável de pesquisadores (SWALES, 1990; IVANIČ, 1998; HYLAND, 1999, 2005; THOMPSON, 2001; BOCH; GROSSMANN, 2002; POLLET; PIETTE, 2002; WHITE, 2004; BOCH; RINCK, 2007; PETRIĆ, 2007, 2012; RINCK, 2010; BOCH, 2013, 2015, para citar alguns mais reconhecidos) das ciências da linguagem, notadamente em contextos francofono e anglofono, preocupados em compreender especialmente a organização e o funcionamento de textos científicos, mas também em pensar o trabalho com esse recurso linguísticodiscursivo na prática didático-pedagógica com tais textos.

No Brasil, contudo, essa temática não tem recebido ainda um tratamento tão consequente e produtivo em manuais de metodologia do trabalho científico e de redação científica que circulam entre nós. Podemos arriscar dizer ainda que, no contexto

\footnotetext{
* Doutor em Linguística e Língua Portuguesa pela Universidade Estadual Paulista Júlio de Mesquita Filho. Professor do Departamento de Letras Estrangeiras da UERN, Campus de Pau dos Ferros, e do Programa de Pós-Graduação em Ensino. E-mail: cezinaldobessauern@gmail.com
} 
brasileiro, a temática não tem recebido a devida atenção em pesquisas da área, a despeito do fato de saber citar ser fundamental para a qualidade dos textos científicos e para o sucesso acadêmico, bem como das dificuldades constatadas no gerenciamento de vozes em textos dessa natureza, produzidos seja por estudantes universitários, seja por pósgraduandos.

Nesse contexto é que se insere nosso interesse pelo estudo da escrita acadêmicocientífica, sobretudo pelo fenômeno da citação, em especial de pesquisadores em seu percurso de formação na vida acadêmica, da iniciação científica à formação na pósgraduação. Tal interesse, iniciado em nossa pesquisa de mestrado (BESSA, 2007), vem se instensificando com a publicação de textos, individual e coletivamente (BESSA, 2011a, 2011b; BERNARDINO; BESSA; NASCIMENTO; CARVALHO, 2012; BESSA; BERNARDINO; NASCIMENTO, 2012), e com a realização de leituras e reflexões que conduziram à nossa investigação no doutorado (BESSA, 2016a).

Buscando ampliar os horizontes de compreensão do fenômeno da citação, este texto faz parte de um estudo no qual objetivamos examinar, pelo viés dos estudos enunciativos e discursivos, os diálogos que constituem o dizer do jovem pesquisador na escrita do texto científico, procurando compreender como esses diálogos colaboram com a construção de uma voz autoral nessa escrita e com a formação do sujeito-pesquisador.

No percurso teórico-analítico do desenvolvimento de nossa tese, demo-nos conta da necessidade de problematizar discursos que emergem da/na esfera acadêmicocientífica sobre o uso de citações na escrita de textos próprios dessa esfera, tal como se configura na proposta do presente trabalho. Fundamentados na visão bakhtiniana1, segundo a qual os valores ideológicos constituem a linguagem humana, e em estudos que abordam a escrita científica, sobretudo em perspectiva enunciativa e discursiva, este texto constitui um recorte de uma discussão que fazemos, no nosso trabalho de doutorado, sobre a dimensão valorativa que subjaz ao discurso sobre o uso das citações nas práticas comunicativas da esfera acadêmico-científica.

Partimos da compreensão de que é fundamental abordar essa questão, sobretudo explorando uma leitura mais crítica quanto à presença e adoção de manuais de metodologia do trabalho científico e de redação científica com viés meramente técnico e prescritivo em cursos na graduação e na pós-graduação, especialmente porque, via de regra, não costumam ser feitas ressalvas e/ou esclarecimentos em relação aos conteúdos e valores que tais manuais expressam. Esse enfrentamento encontra respaldo no entendimento, assumido em Bessa (2016a), de que a dimensão valorativa tem fortes determinações sobre o modo como o jovem pesquisador se relaciona dialogicamente com autores e posições teóricas que cita em seu texto e, por decorrência, sobre a construção da voz autoral desse pesquisador na escrita científica.

\footnotetext{
${ }^{1}$ Esclarecemos aqui que, dada a necessidade de priorizar o trabalho analítico realizado, não consta, no presente texto, uma seção específica para apresentação dos fundamentos teóricos. Limitamo-nos a destacar que nossa reflexão tem os pressupostos teóricos que balizam a abordagem dialógica da linguagem do Círculo de Bakhtin (BAKHTIN, 2003, 2010a, 2010b, 2010c; MEDVIÉDEV, 2012; VOLOCHÍNOV, 2013), com destaque para a concepção de linguagem e noções como signo ideológico, sujeito e enunciado, como ancoragem teórica central.
} 
Assumimos, além disso, que a dimensão valorativa que subjaz ao uso das citações como concebemos aqui é da ordem de um dizer que reflete e refrata valores de uma cultura acadêmico-científica que preconiza determinadas posturas, concebidas como desejáveis e/ou ideais, nas práticas comunicativas do jovem pesquisador. Assumimos, assim, que tais posturas, em geral de natureza prescritiva, se encontram em consonância com os padrões de cientificidade e convenções próprios de uma esfera acadêmico-científica que visa, em grande medida, a engessar as marcas do estilo individual do produtor e a cercear uma maior liberdade, necessária ao processo criativo do autor na escrita de textos científicos.

Essa dimensão se expressa geralmente sob a forma de um discurso que sustenta um "como fazer" citações e que emana, na maioria das vezes, da voz que constitui as orientações de manuais de metodologia do trabalho científico e de redação científica, mas que encontra também, em discursos e práticas comunicativas de sujeitos (professores e/ou pesquisadores) do universo acadêmico, lugar para sua manifestação e proliferação.

Além de suscitar alguns questionamentos para pensar mais profundamente sobre a questão e instigar o debate, abrindo perspectivas para outras problematizações, nosso propósito aqui é, em última instância, pontuar alguns desses valores e refletirmos sobre eles, numa perspectiva de trazer alguma contribuição para o trabalho com 0 gerenciamento de vozes na escrita de textos científicos, com foco voltado sobretudo para a escrita de jovens pesquisadores. Procuramos, assim, reafirmar, na linha de Rinck e Mansour (2014), a dimensão complexa que constitui o citar, especialmente para o jovem pesquisador, num contexto acadêmico-científico notoriamente marcado por "dimensões "escondidas"' (STREET, 2010) e por exigências contraditórias, paradoxais (BOCH; GROSSMANN, 2002; POLLET; PIETTE, 2002) que atravessam suas práticas comunicativas.

Além desta introdução, em que buscamos apresentar problemática, objetivo e justificativa do trabalho, e sinalizamos a fundamentação teórica adotada, o presente texto traz uma seção em que se centra em especial na análise de manuais de metodologia do trabalho científico e de redação científica recortados, na qual consta também uma breve descrição metodológica. Por fim, temos a seção de conclusão, em que tecemos algumas considerações sobre os achados do trabalho e acerca do direcionamento do trabalho com a citação na universidade com foco nos jovens pesquisadores.

\section{DAS VALORAÇÕES EM DISCURSOS SOBRE O USO DE CITAÇÕES NA ESCRITA DE TEXTOS CIENTÍFICOS}

Pautando-nos na compreensão bakhtiniana segundo a qual todo dizer se constrói dialogicamente e é axiologicamente valorado, entendemos aqui, pois, que cada autor dos manuais de metodologia do trabalho científico e de redação científica reportados em nosso estudo são vozes sociais, são sujeitos que participam de um diálogo. Assim, esses sujeitos, ao discursivizarem sobre escrita científica e sobre citações, assumem posicionamentos axiologicamente valorados, orientados por determinados modos de compreender o que é escrever um texto científico, bem como o que é a construção de um 
conhecimento científico, seja, por exemplo, no campo das ciências naturais, seja no domínio das humanidades. É, portanto, orientados por essa compreensão que passamos a explorar, nesta seção, alguns valores que subjazem aos discursos sobre o uso de citações na escrita científica identificados no estudo que fizemos em nossa tese.

Para darmos sustentação a esta exposição, que se ancora em uma pesquisa de natureza interpretativa (BESSA, 2016a), seguindo definição de Laville e Dionne (1999), e em uma abordagem qualitativa de pesquisa, recorremos a um exame feito em alguns manuais de metodologia do trabalho científico e de redação científica que circulam no universo acadêmico e no mercado editorial de nosso país, dentre os quais destacamos, por exemplo, Introdução à metodologia do trabalho científico: elaboração de trabalhos na graduação (ANDRADE, 1999) e Redação científica: a prática de fichamentos, resumos, resenhas (MEDEIROS, 2006). Pode-se asseverar que os manuais recortados para exame aqui sejam facilmente identificáveis como pertencentes ao leque daqueles frequentemente encontrados em nossas universidades e citados em trabalhos científicos, da graduação à pós-graduação. Tais manuais foram aleatoriamente escolhidos e sem preocupação sistemática, até porque não se trata de um estudo com viés quantitativo e com pretensão de generalização. Desses manuais recortamos, portanto, alguns fragmentos/enunciados que serão utilizados, ao longo da exposição, para fins de demonstração e compreensão de como a maioria desses valores se manifesta.

Além disso, reportamo-nos a contribuições e a reflexões de alguns pesquisadores que abordam a temática da escrita do texto acadêmico-científico e que focalizam, em alguma medida, o uso de citações nessa escrita e/ou que fornecem instruções sobre seu uso. Dessa forma, procuramos observar também as vozes daqueles que mais diretamente estudam a escrita científica, por entendermos que seus discursos influenciam leituras e práticas de professores e alunos em nossas universidades.

Ao longo da exposição que segue, optamos, em alguns momentos, por não tomar alguns desses valores separados de outros, dado o nosso propósito de tentar realçar a ideia fundamental de exigências paradoxais que, via de regra, presidem as orientações/prescrições sobre o uso das citações na escrita de textos científicos. Feitas essas considerações preliminares, passemos, então, à exposição.

Os dois primeiros valores estão relacionados à quantidade de citações que um pesquisador pode/deve fazer em seu texto científico. De um lado, encontra-se evitar $o$ excesso de citações; de outro, evitar a escassez de citações. Assim, de um lado está o temor de que o texto possa não apresentar contribuição pessoal do autor e pareça muito mais uma "colcha de retalhos", de maneira a configurar "uma redação deficiente" (ANDRADE, 2009, p. 92); de outro, está a preocupação com que o texto possa se constituir tão somente de impressões pessoais e/ou que omita que determinadas palavras e ideias pertencem a outrem, com prejuízo para os padrões de cientificidade e até mesmo das questões éticas na comunicação científica. Nesse sentido, são frequentes recomendações e orientações do tipo: "Cite pouco e reescreva muito" (AZEVEDO, 2008, p. 119) e "o uso de citações é importante e adequado desde que não atribua ao trabalho o caráter de cópia ou mera colagem” (CHAROUX, 2004, p. 79).

Há quem, como Andrade (2009), afirme que não se deve exagerar na quantidade de citações, bem como quem pense que evitar extremos seja a melhor opção. Quanto a este 
último entendimento, destacamos a posição de Santos (2007), para quem um trabalho sem uso de citações pode configurar um texto meramente opinativo (um ensaio científico, por exemplo), assim como um trabalho com citações em excesso pode causar a impressão de "colcha de retalhos".

Se, por um lado, o excesso de citações pode sugerir colagem ou remix, com pouca contribuição pessoal, a escassez delas pode, por outro lado, indicar que determinados empréstimos ao discurso do outro podem não estar sendo explicitados na superfície textual, configurando, por vezes, defeito de notação de fonte (POLLET; PIETTE, 2002) e/ou certos tipos de plágio ${ }^{2}$ - como as falsas paráfrases, nos termos de Eco (2001) - tal como esse fenômeno é concebido em seu sentido usual na literatura. Isso demonstra o quão complexa e arriscada é, portanto, a tarefa de tentar definir uma "medida certa", se é que ela existe, quanto ao uso das citações, sem considerar, antes, as especificidades, as dimensões contextuais e cotextuais, os propósitos e condições de produção de cada trabalho.

A propósito, é pertinente observar o que afirma Sánchez (2013) sobre a relação entre a quantidade de citações e a qualidade em um texto científico. Mesmo que se referindo ao aspecto das funções retóricas das citações em um contexto de pesquisa mais específico, de um estudo comparativo entre textos de filipinos e de espanhóis, a afirmação do autor segundo a qual não é conveniente confundir a quantidade elevada de citações em uma pesquisa com a qualidade do estudo pode, certamente, ser pensada para as práticas mais gerais que recobrem o uso das citações na escrita científica. O argumento do autor, com o qual concordamos plenamente, é que a quantidade de citações deve estar justificada pelo uso consciente em cada momento, em cada seção do texto do pesquisador, e conforme, acrescentamos, os propósitos do trabalho.

Isso não significa dizer que a quantidade de citações não deva ser, em muitos casos, considerada, de fato, um problema que pode comprometer a qualidade do texto. Um bom exemplo é o da manifestação daquilo que Pollet e Piette (2002) denominam obsessão citacional, que compreende aqueles casos em que, em textos de estudantes iniciantes na escrita científica, os dizeres do outro são reproduzidos sem haver reformulação, e, mais frequentemente, ocultando completamente o escritor/autor reportado. Conforme as autoras, essa prática ocorre, portanto, quando o escritor cita informações banais, que não se justificariam e não apresentariam nada de original, mas também quando constrói um texto que parece mais uma "colcha de retalhos", pelo fato de não fazer mais que aderir ao discurso do outro, sem, algumas vezes, nem mesmo explicitar as relações entre os autores citados.

Outros dois valores marcantes sobre o uso de citações compreendem evitar a reprodução literal de dizeres e o incentivo à reformulação de dizeres. $\mathrm{O}$ primeiro deles diz respeito à ideia de evitar citações diretas, enquanto que o segundo se relaciona à ideia de que, para fugir à reprodução literal de palavras, é necessário que o pesquisador realize paráfrase ou citação indireta, ou seja, que ele exprima, com as "próprias" palavras, o dito por outrem.

\footnotetext{
${ }^{2}$ Podemos pensar aqui o caso do que Pecorari (2008) denomina de patchwriting, um procedimento típico de "repetição do uso da linguagem", que ocorre, segundo ela, quando escritores inexperientes não têm uma voz autoral suficientemente competente para não se prenderem à linguagem dos outros, dos escritores mais proficientes.
} 
Ajudam-nos a comprovar a força desses dois valores no universo acadêmicocientífico enunciados tais como: "[...] faça poucas citações diretas; opte por reescrevêlas, creditando-as aos seus autores" (AZEVEDO, 2008. p. 120), "deve-se fazer uso das citações longas com cautela. É preferível que o aluno sintetize e escreva a ideia com suas próprias palavras e informe sua origem" (CHAROUX, 2004, p. 79, grifos nossos) e "autores experientes evitam [...] a composição de um novo texto com frequentes transcrições" (MEDEIROS, 2006, p.181).

Nesses termos, a reformulação do dizer é concebida como uma das formas de empréstimo das palavras de outrem mais valorizadas na esfera acadêmico-científica. Rinck e Mansour (2013) assinalam, por exemplo, que a reformulação é mais valorizada, numa comparação com acitação literal, porque aquela permite indicar as fontes sem seu próprio nome, de modo que aquele que escreve não se restringe a copiar, a transcrever. Mas não entendamos que essa valorização se dê por, conforme parecem sugerir Diniz e Terra (2014), ser a paráfrase considerada "um exercício criativo do leitor que se lança como autor" (p. 79), como se o uso da citação literal não pudesse se dar também de forma criativa e, por conseguinte, venha a representar um gesto (menos) autoral.

Se se considera que a reformulação de dizeres seja uma estratégia, digamos, mais desejável, porque se supõe mais autonomia da parte do pesquisador (POLLET; PIETTE, 2002), é pertinente ponderar que a reprodução literal de palavras pode ser compreendida como um estágio necessário no desenvolvimento do letramento acadêmico e na aquisição de um discurso disciplinar, como se depreende a partir de estudo de Petrić (2012), no qual a autora investiga o uso da citação direta ${ }^{3}$ em textos de pesquisadores iniciantes, mais precisamente de estudantes de mestrado.

Numa perspectiva bem próxima dessa concebida por Petrić (2012), encontra-se a reflexão de Rinck e Mansour (2013) sobre a prática do copiar-colar na escrita de estudantes universitários, que essas autoras defendem como uma prática de letramento no contexto dos letramentos universitários. Elas entendem que o copiar-colar permite interrogarmo-nos sobre o desenvolvimento de competências de letramento em termos de aculturação. É o caso, pois, de propormos que evitemos os extremos, sugerindo como caminho para o enfrentamento dessa questão instruções voltadas para o uso consciente de uma ou outra forma de citar, observando-se aspectos como, por exemplo, a condição/estágio de formação do pesquisador, a complexidade da temática tratada e a natureza do texto.

Outro valor importante, possivelmente aquele mais insistentemente proclamado no universo acadêmico e que naturalmente se justifica pela própria natureza do fazer científico, é assumir posição crítico-reflexiva. A crítica que se faz, no universo acadêmico-científico, ao pesquisador que se limita a reproduzir ideias e que não produz uma "reflexão pessoal", encontra seu fundamento na defesa de um pesquisador com autonomia, criatividade e originalidade, um pesquisador capaz de construir um saber

\footnotetext{
${ }^{3}$ Com relação à dimensão pedagógica que recobre o uso da citação direta na escrita científica, é pertinente sublinhar que Petrić (2012) contraria orientações/recomendações de manuais de metodologia científica e muitas práticas de professores, sustentando que não seria produtivo simplesmente advertir os estudantes a não fazerem uso excessivo de citações diretas sem que se identifique o problema subjacente e se forneça instruções direcionadas para a causa.
} 
fundado na elaboração de posicionamentos próprios e no estabelecimento de distância crítica (REUTER, 1998; POLLET; PIETTE, 2002; RINCK; MANSOUR, 2013) em relação aos autores que cita e às posições teóricas reportadas. Em outros termos, trata-se de um pesquisador que, dentre outras posturas, problematiza, questiona, interpreta e comenta o dizer do outro que toma emprestado, enfim, um pesquisador que, no diálogo com as outras vozes com as quais interage, revela uma tomada de posição que se pode denominar crítico-reflexiva. Isso fica evidente nos seguintes enunciados de alguns manuais de metodologia do trabalho científico e de redação científica: "Os autores e materiais utilizados devem ser usados criticamente, mantida a distância entre eles e o autor do novo texto. Um texto científico não é e nem pode parecer uma colagem" (AZEVEDO, 2008, p. 108, grifos nossos) e "Ao apoiar-se em uma citação literal para inserir no trabalho, o autor deve preocupar-se em transmitir sua interpretação sobre a referência e comentá-la para, desta forma, apropriar-se do pensamento em que se apoiou, ressaltá-lo e inseri-lo no novo contexto" (CHAROUX, 2004, p. 79, grifos nossos).

Entre pesquisadores que se dedicam ao estudo da escrita científica, notadamente no domínio dos estudos da linguagem, mas não apenas nele, há também uma clara defesa de que, ao produzir um texto científico, o pesquisador não pode "esconder-se atrás dos autores [que cita]" (DEMO, 2009, p. 71), tampouco deixar de se posicionar - realizando julgamentos, questionando o mérito do dizer do outro - na discussão que instaura em seu texto, como revela Machado (2002), a propósito da revisão de literatura em trabalhos de pós-graduandos, quando comenta texto de outra autora que trata dessa questão:

\begin{abstract}
Essa autora desenvolve uma ideia muito interessante, ao considerar que essas dificuldades dos alunos, resultam em textos que não passam de colagens de citações dos autores preferidos, têm a ver com a sua incapacidade de julgamento, que ela classifica de aderência ou rejeição às ideias de outrem. Poderíamos traduzir seus termos por uma tomada de posição. Diante de um saber que nos é apresentado, podemos simplesmente acreditar neles, assimilá-lo como se fosse verdadeiro, sem entrar no mérito de sua validade. Outra postura que ela sugere é julgá-lo pertinente e inadequado e desenvolver argumentos para elucidar nossas posições no diálogo com os autores e suas formulações. É esse patamar, que podemos chamar propriamente de teórico ou crítico, que os alunos não galgam facilmente. (MACHADO, 2002, p. 75, grifos nossos).
\end{abstract}

Seguindo uma linha muito parecida, mas centrado em um estudo comparativo acerca das funções retóricas das citações em textos científicos de escritores espanhóis e filipinos, Sánchez (2013) explicita algumas posturas desses escritores que ajudam a confirmar o lugar essencial que a ideia de assumir posição crítico-reflexiva adquire na escrita científica. $\mathrm{O}$ autor constata que há tanto escritores que renunciam a polemizar com as fontes, gerar controvérsias ou fazer críticas negativas, quanto há também aqueles que manifestam opiniões e valorações sobre as citações que apresentam em seus textos.

Podemos sintetizar dizendo que, em ambos os casos, o que está em questão são posturas que recobririam, muito provavelmente, aquilo que Bourdieu (2005) denomina estabelecer uma relação de desfetichização com os autores, propondo que, sem deixar de estabelecer uma relação respeitosa com eles, incluindo aí os grandes pensadores, é preciso submeter sempre as citações à crítica, examinar sua função, sua verdade e sua validade. 
Bazerman (2007), por sua vez, sinaliza que, na contramão dos trabalhos repletos de corta-e-cola de citações, paráfrases e plágios literais, se deva valorizar as experiências de ensino centradas em produtores de textos científicos bem-sucedidos, que, no caso, sejam capazes de interpretar e reelaborar o que as fontes citadas têm a dizer, que avaliem, comentem, sintetizem e que produzam um argumento novo. Como podemos observar, são posturas que se relacionam mais diretamente ao empréstimo de fontes, mas que remetem, inevitavelmente, às questões de autoria, pautadas, cada vez mais, numa escrita com mais contribuição pessoal, liberdade criativa e originalidade, marcada pela elaboração de posicionamentos próprios que, em última instância, revelem o espírito crítico-reflexivo do pesquisador.

Dada a possibilidade de potencializar a formação do pesquisador e a qualidade de sua produção científica, acreditamos que tais posturas precisam ser mais encorajadas e exploradas no processo de formação em pesquisa e na escrita do texto científico do jovem pesquisador. Concordando com Pollet e Piette (2002), defendemos que o trabalho sobre a citação e a reformulação do discurso do outro na escrita do texto científico, explorando aspectos como a cultura da disciplina, sua história, suas práticas de pesquisa e de escrita científica (incluindo também os valores sobre o uso de citações, como discutidos neste trabalho), pode contribuir para o desenvolvimento dessa postura crítico-reflexiva.

Dentre os valores que suscitamos se encontram dois que estão diretamente relacionados à autoridade do autor citado, quais sejam: citar autores de renome ou citar comentadores. Entendemos como de renome aqui, por exemplo, os autores que são denominados clássicos e/ou autores que poderíamos traduzir, por falta de melhor termo, por "autores de referência". Já como comentador entendemos o pesquisador especializado em determinado autor/obra e que foza de notório reconhecimento entre os pares.

Embora não seja comum encontrarmos os referidos valores em manuais de metodologia do trabalho científico e de redação acadêmica, eles se manifestam no discurso e na prática de produção do conhecimento da esfera acadêmico-científica, sobretudo em contextos de orientação e de exames de qualificação e em sessões de defesa de monografias, de dissertações e de teses.

Citar autores de renome se sustenta na ideia de que citar autores conforme sua maior importância e mais prestígio na área do saber tem fortes implicações para a credibilidade do trabalho. O manual de Santos e Filho (1998, p. 258) sustenta essa ideia, ao afirmar que "as citações, quando de autores de renome, servem não somente para enriquecer o trabalho, mas principalmente para dar maior credibilidade aos argumentos do pesquisador", numa clara evidência de que o trabalho se fortalece, quando o pesquisador faz referência aos autores mais conhecidos e citados na sua área.

Tomemos um exemplo. Citar o sociólogo francês Pierre Bourdieu, considerado um dos maiores pensadores do século XX, em uma discussão que trata, por exemplo, de relações de poder no campo científico, é bem diferente, no que se refere à força argumentativa que o trabalho pode adquirir e ao respaldo, de citar um comentador, a menos que este tenha desenvolvido uma tese bem fundamentada que avance a reflexão daquele e que tenha se constituído como referência entre os pares. Seguindo esse mesmo raciocínio, citar um comentador é igualmente diferente de citar um jovem pesquisador 
(um doutor sem tanto prestígio na área ou um doutorando, por exemplo) que utiliza Bourdieu, para tratar de uma problemática relacionada à temática já referida. Ocorre aí que o pesquisador tende, como aponta estudo de Coracini (2007), a obedecer a um critério de seleção que leva em conta o respaldo do autor citado - em sua área disciplinar escolhendo, quando houver mais de um nome a citar, o mais conhecido, o mais famoso, como condição determinante para conseguir apoio significativo para os argumentos.

Deixar de considerar essas nuanças é, evidentemente, possível, embora não seja desejável, seja por uma opção do próprio pesquisador e/ou de seu orientador, seja por este não ter acesso ao texto-fonte do autor de renome, seja ainda por mais completo desconhecimento acerca da credibilidade que um texto científico adquire quando cita o autor de renome e não um comentador.

Diniz e Terra (2014), por exemplo, afirmam que "os comentaristas exercem um papel fundamental no processo pedagógico e na circulação de ideias, mas são autores sem expectativas de ser citados" (p. 145), posição da qual discordamos, porque acreditarmos que, por vezes, o comentador suscita questões que podem, dentre outros aspectos, ampliar o horizonte de compreensão do texto do autor de renome. Nossa restrição é quanto àqueles casos em que o jovem pesquisador se limita a citar os comentadores, abdicando do estabelecimento de um diálogo com os textos de autores de referência.

O que deve ser determinante é considerar, por exemplo, o tipo de informação/ideia que se pretende citar e em qual seção do texto/trabalho, se em uma introdução, se em uma seção teórica, e com que finalidade, para ponderarmos sobre a possibilidade de fazermos uso ou não do texto do comentador. Em casos, por exemplo, em que o produtor necessite citar um conceito ou definição de uma determinada perspectiva teórica, seria prudente recomendar e ou orientar que o pesquisador citasse, de fato, o autor do texto-fonte e não os comentadores. Isso não é incompatível, porém, com o caso de o produtor poder citar comentadores explicitando as diferentes compreensões que eles constroem sobre um dado conceito ou posicionamento de uma determinada perspectiva teórica, assim como colocar autor de renome e comentadores em diálogo, conforme fazem, inclusive, muitos pesquisadores experientes. Ter em vista essas especificidades e explicitá-las para o jovem pesquisador é uma condição muito mais prudente e produtiva que simplesmente assumir deliberadamente que se deve evitar citar os comentadores.

Outros valores sumamente importantes que atravessam o discurso sobre o uso das citações no universo acadêmico-científico e que geralmente não costumam ser explicitados em manuais de metodologia do trabalho científico e/ou de redação científica, mas que fazem parte de uma espécie de "acordo tácito" entre pesquisadores, sobretudo daqueles mais experientes, são apontados a seguir. É importante frisar que eles estão mais diretamente relacionados aos aspectos das "regras do jogo" do universo acadêmico do que propriamente às competências escriturais do pesquisador, tal como é também a questão de citar ou não autores de renome, que acabamos de evocar.

- priorizar citações de trabalhos mais recentes - o quão recente é um texto científico que o pesquisador cita em seu trabalho indica o esforço de atualização em relação às reflexões e aos avanços das pesquisas da área em um dado domínio disciplinar. 
Motta-Roth e Hendges (2010) afirmam que o aspecto do quão recente é um texto tende a adquirir mais importância conforme áreas e disciplinas assumam uma tendência de valorizar ou não o saber acumulado ao longo do tempo. Elas acrescentam que em disciplinas específicas como filologia ou história, que apresentam uma visão diacrônica do conhecimento, esse aspecto já não é tão determinante.

Às vezes, portanto, é imprescindível considerar a diacronia do conhecimento para que sejam evitadas compreensões equivocadas e/ou parciais de um dado objeto, fenômeno. Mas, evidentemente, não se pode descartar que, na maioria das áreas do saber, os trabalhos mais recentes não devem ser ignorados; pelo contrário, precisam mesmo ser mais valorizados, tanto quanto textos considerados clássicos, sobretudo quando se tem em vista que o avanço na construção do conhecimento implica considerar o diálogo com as produções mais recentes dos pares.

Assim, para citar um exemplo hipotético, podemos pensar que um trabalho de um pesquisador/estudioso sobre um problema $X$, publicado na mais recente edição de um periódico científico e que aponte uma nova leitura/compreensão sobre uma questão formulada anteriormente e sustentada por longo tempo, tende, necessariamente, a constituir uma citação obrigatória, sobretudo em determinadas áreas do conhecimento (como a robótica, a medicina, dentre outras), dado o fato de se tratar de um saber mais atualizado. Com isso, reforçarmos a importância de encorajarmos os jovens pesquisadores a citarem tanto os textos clássicos, quanto as produções mais recentes, enquanto possibilidade de ampliação do olhar sobre as problemáticas pesquisadas e da construção de uma visão mais ampla do domínio do saber no qual ele se situa.

- priorizar citações de trabalhos conforme a qualidade da fonte de publicação - no contexto atual de publicações científicas em larga escala, tem sido cada vez mais corrente avaliar a qualidade de um artigo científico, e, portanto, sua credibilidade, a partir da fonte de sua publicação, que, em nossa cultura acadêmica, é o periódico científico.

Esse aspecto não deixa de estar diretamente associado à lógica de valorização de publicação de artigos científicos em periódicos de maior prestígio no universo acadêmico, logo, como observa Silva (2009, p. 120, grifos nossos), “à exigência de publicar soma-se a necessidade de identificar 'onde publicar'”. Por conseguinte, a exigência de qual artigo citar está, em grande medida, sobretudo entre pesquisadores considerados experientes, determinada pela identificação do prestígio (entenda-se, dentre outros parâmetros, fator de impacto e/ou qualis-CAPES mais elevado) do veículo onde ele foi publicado.

Se o artigo é publicado em um periódico científico com alto fator de impacto, se apresenta indexação, e se, no caso do Brasil, a depender da área do conhecimento, está bem qualificado no sistema Qualis-CAPES, determina o seu "valor" no "mercado das citações". Exemplificando: se, na grande área de Letras e Linguística em solo brasileiro, um artigo X é publicado em uma revista com Qualis-CAPES A1, que é o estrato mais elevado desse sistema de avaliação e teoricamente reservado aos artigos de maior qualidade, pressupõe-se que este seja um artigo de excelência, e, por conseguinte, este apresenta muito mais chances de ser citado por um pesquisador do que outro artigo publicado em uma revista com um estrato diferente, de menor valor. 
Nessa mesma linha de compreensão, um artigo que consta de uma coletânea de livro publicado em editora pouco conceituada ou quando publicado em um blog tende a ser preterido em relação a um artigo veiculado em um periódico Qualis-CAPES A1. A recomendação é citar trabalhos de bons autores, com prestígio entre os pares, publicados em bons periódicos, de preferência naqueles de mais visibilidade, inclusive de alcance internacional, que gozam de mais respeitabilidade na esfera acadêmico-científica.

Nesses casos, portanto, pensando na credibilidade de seu texto, o pesquisador tende a citar o trabalho mais bem avaliado pelos pares, o que, geralmente, está atrelado à qualidade do seu meio de divulgação, até porque, da mesma maneira, quando se trata de definir onde publicar, "o objetivo de publicizar, tornar público, é condicionado pelo tipo de veículo. Em tese a qualidade do que é produzido é garantida pela qualidade do periódico que veicula." (SILVA, 2009, p. 120).

- incentivo à citação de trabalhos em coautoria - reflexo de um universo acadêmico-científico "globalizado", a defesa mais recente do estabelecimento de redes de pesquisa e de colaboração sem fronteiras entre pesquisadores ${ }^{4}$ faz pensar, dentre outras questões, que um artigo científico assinado por dois ou mais pesquisadores supõe uma contribuição mais relevante para a área, já que, teoricamente, em virtude do diálogo estabelecido entre eles e, muitas vezes, da amplitude e do alcance do estudo, o resultado pode ser um trabalho mais rico e consistente, e, portanto, de maior respaldo e credibilidade entre os pares.

Se o incentivo aos trabalhos em coautoria, e, por conseguinte, de citação desses trabalhos, é inegavelmente uma questão que tende a ser valorizada mais em determinadas áreas do conhecimento, principalmente naquelas em que o espírito de parcerias entre grupos de pesquisa é uma prática mais bem consolidada, ela já começa a ganhar força também em outras áreas, inclusive na grande área de Letras e Linguística, como reflexo, sobretudo, das políticas implementadas pela CAPES e por órgãos de fomento à pesquisa em relação à avaliação da produção científica dos pesquisadores brasileiros.

Considerando que não são tão expressivas as iniciativas de parcerias entre grupos de pesquisa em nossa área, podemos arriscar dizer que, diferentemente de outras áreas do conhecimento como é o caso da medicina, a forma de coautoria ${ }^{5}$ que, geralmente, é praticada na grande área de Letras e Linguísticaainda se dá entre orientador e orientando, sobretudo no contexto mais recente de exigência, aqui no Brasil, de que, para publicar um artigo científico em um periódico com avaliação mais elevada no Qualis-CAPES, o pósgraduando deveria "assinar" o texto com um parceiro com título de doutor. Basta realizarmos uma rápida consulta às normas de alguns periódicos nacionais mais bem qualificados para constatarmos prescrições tais como: "Os trabalhos devem ser

\footnotetext{
${ }^{4}$ A ideia de colaboração e redes de pesquisa na atividade de produção e difusão do conhecimento em um nível global encontra respaldo em afirmações como essa de Goergen (2002, p. 250, grifos nossos): "Em termos da pesquisa ou produção do conhecimento, observa-se que, em razão da complexidade, da dimensão e mesmo dos custos dos projetos de investigação, esses são desenvolvidos não mais por pessoas individuais, mas por grupos de pesquisa. Essas equipes, por sua vez, são integradas por investigadores de diversas regiões e países, de culturas e línguas diferentes.".

${ }^{5}$ Não se pode negar que, em boa medida, são frequentes as parcerias entre colegas de trabalho de um curso/departamento/programa de pós-graduação e/ou grupo de pesquisa.
} 
apresentados por doutores. Quando o autor for doutorando, mestre ou mestrando, deve haver a coautoria de um doutor" ou "São aceitos trabalhos em que pelo menos um dos autores tenha o título de doutor. Mestrandos, mestres e doutorandos podem submeter artigos com a condição de que sejam co-autores com pesquisadores doutores".

Esse é um tipo de postura que pode ter um desdobramento preocupante para a atividade de pesquisa em tempos de exigência de produtividade em larga escala, já que, dentre outras questões, tal postura pode induzir a autorias forjadas ou, se preferirmos, autorias presenteadas, nos termos de Diniz e Terra (2014), tendo em vista que, conforme salienta Paiva (2015), nem sempre o tipo de colaboração que o orientador presta - como se dá, por exemplo, em um artigo científico resultante de uma dissertação ou tese justifica o crédito da coautoria no trabalho do orientando. Esse entendimento de Paiva (2015) também é compartilhado por Silva (2009, p. 122), que entende isso como reflexo das exigências de produtividade dos órgãos superiores em relação à pós-graduação:

\footnotetext{
Não é por acaso que nas ciências humanas adota-se uma prática muito comum em outras áreas, a qual consiste em aparecer como co-autor nos artigos dos orientandos. Muitas vezes, a co-autoria não se justifica e uma simples nota de agradecimento no rodapé faria justiça ao orientador, mas isso não conta ponto. Em nome da sobrevivência do programa e das necessidades docentes, entra-se no reino do vale tudo.
}

Para exemplificar essa prática, citemos a situação (quase) fictícia, trazida por Vilaça e Pederneira (2013, p. 235), bastante sugestiva dessa questão:

\footnotetext{
Primeiro ato: A mestranda e a descoberta

- "E aí, tem publicado?", indaga-se a uma mestranda.

Sem hesitar, ela responde:

- "Não! As revistas não publicam textos de quem não tem doutorado".

- "Mas e se você convidar a sua orientadora para assinar o artigo?", sugere-se a ela.

- "Boa ideia!", ela exclama, como se descobrisse os passos para ascender ao paraíso dantesco.
}

Depreende-se disso que o incentivo à citação de trabalhos em coautoria, que poderia ser um expediente produtivo e enriquecedor em todas as áreas do conhecimento, se apresenta na prática, muitas vezes, como uma questão bastante complexa, e não pouco importante, no cenário atual, em especial porque ela passa a suscitar, em virtude desse "reino de vale tudo", a discussão sobre assinatura e autoria científicas. O que se coloca aí é que essa discussão implica trazer o debate para o terreno das questões sobre ética e de integridade em pesquisa, questões essas que, infelizmente, prescindem ainda de um enfrentamento mais consequente no universo acadêmico-científico nacional, notadamente no domínio das ciências humanas e especialmente na grande área de Letras e Linguística, no qual ele se insinua, muito timidamente ainda, por meio de algumas poucas vozes dissonantes.

Essas vozes, discursos, posicionamentos e práticas suscitados aqui sinalizam em boa medida a condição complexa do estudante que se inicia no universo da pesquisa e da 
escrita acadêmico-científica. É evidente que se pode pensar que esse estudante, pesquisador em formação, tende a ir se familiarizando, paulatinamente, com as convenções e regras do jogo acadêmico, e que recobrem a prática da escrita científica e do citar em particular.

Entendendo, pois, que o aprendizado da escrita científica e principalmente do manejo de vozes nessa escrita diz respeito a um processo demorado e complexo, como assumem Boch e Grossmann (2002) quando afirmam que "o tempo da escrita teórica é um tempo longo, que supõe conceptualização e apropriação" (p.107), e quando afirmam ainda que "a escrita pessoal passa por uma gênese complexa, na qual o papel das referências e citações pode evoluir sensivelmente", nossa leitura aqui aponta para a importância de olharmos mais criticamente para discursos e práticas que colaboram para potencializar as dificuldades que estudantes, jovens pesquisadores, enfrentam quando confrontados com a necessidade de estabelecerem diálogo com autores e de usarem fontes, fazendo citações adequadas e de modo pertinente, na escrita científica.

Entendemos que, em vez de nossas constantes queixas quanto ao uso pouco produtivo de citações nos textos de nossos estudantes, é preciso, antes de tudo, reconhecermos que citar, na escrita científica, é, por natureza, um ato complexo, como pontuam Rinck e Mansour (2013). Isso supõe termos em vista, por exemplo, que escolher qual autor citar implica avaliar, interpretar e se posicionar, posturas que, no caso do jovem pesquisador, tendem a ser enfrentadas com maior dificuldade, sobretudo porque eles precisam ainda considerar os desníveis, que nem sempre são conscientes, das posições que ele e que os autores que ele cita ocupam em seu campo de saber.

É preciso considerar ainda que certos discursos, materializados em manuais de metodologia do trabalho científico e de redação científica, e práticas de pesquisadores e professores disseminam valores, como mostrado aqui, que colaboram para um quadro de exigências paradoxais que pode muito mais confundir e desorientar o estudante que contribuir efetivamente para uma prática comunicativa científica criativa, adequada e relevante. Esse quadro se torna mais complexo quando se leva em consideração a existência de um contexto pedagógico em que, como nos lembram Pollet e Piette (2002), as características da escrita científica, com as quais os estudantes precisam se familiarizar, não são, na maioria das vezes, para eles justificadas e ainda menos ensinadas, tampouco de maneira ativa e participativa.

\section{CONCLUSÃO}

Estamos conscientes de que este texto não esgota as possibilidades de identificação e de exploração de outros valores que se expressam em discursos sobre o uso de citações na escrita acadêmico-científica, tampouco de leituras sobre eles. De todo modo, acreditamos que as opções, as ilustrações e as interpretações que fizemos aqui dão bem uma ideia da dimensão valorativa que perpassa o discurso sobre o "como fazer" citações na escrita do texto científico e o quão complexo indica ser o seu enfrentamento, dada, por um lado, a multiplicação de instrumentos e de práticas que se conjugam para difundi-los e perpetuá-los, e, por outro, a escassez ainda de estudos e reflexões que explorem mais profundamente a questão. 
Não ignorar essa dimensão valorativa que preside o uso de citações nos parece fundamental para uma compreensão mais adequada das condições que regem as práticas de citação e da própria natureza da escrita de textos científicos, bem como das dificuldades com as quais se defrontam os jovens pesquisadores para se familiarizarem com convenções e "regras do jogo" (algumas vezes, confusas; outras vezes, contraditórias e paradoxais) da esfera acadêmico-científica. Isso se faz premente quando consideramos, sobretudo, que muitos dos valores acerca do uso das citações apontados aqui têm implicações diretas sobre o exercício da escrita científica, interferindo, por exemplo, na liberdade criativa do produtor.

Nossas reflexões aqui pretenderam, portanto, suscitar um olhar de mais sensibilidade para com a escrita científica do estudante que se inicia na atividade científica, procurando entender que é preciso considerar tanto a sua condição de sujeitopesquisador em formação na e para a pesquisa científica e que, paulatinamente, vai se familiarizando com o fazer científico e com a escrita de textos do universo acadêmico, quanto à possibilidade de colaborarmos para potencializar esse processo de familiarização.

E, nesse sentido, colocar a discussão sobre o "como fazer" citações no texto científico, que atravessa discursos e práticas do/no universo acadêmico, não só é uma questão necessária, como também imprescindível em nossas investigações e em nossas práticas de ensino de redação acadêmica e/ou de leitura e escrita de textos acadêmicos na universidade, sobretudo para quem assume um compromisso político com a potencialização da qualidade dos textos científicos produzidos por jovens pesquisadores e que são publicados e passam a circular no universo acadêmico.

\section{REFERÊNCIAS}

ANDRADE, M. M. de. Introdução à metodologia do trabalho científico: elaboração de trabalhos na graduação. 9. ed. São Paulo: Atlas, 2009.

AZEVEDO, I. B. de. O prazer da produção científica: descubra como é fácil e agradável elaborar trabalhos acadêmicos. 12. ed. rev. e atual. São Paulo: Hagnos, 2008.

BAKHTIN, M. Problemas da poética de Dostoiévski. Tradução do russo de Paulo Bezerra. 5. ed. Rio de Janeiro: Forense Universitária, 2010a.

Questões de literatura e de estética: a teoria do romance. Equipe de tradução Aurora Fornoni Bernardini et alii. 6. ed. São Paulo: Hucitec, 2010 b. . (VOLOCHÍNOV). Marxismo e Filosofia da linguagem. Tradução de Michel Lahud e Yara Frateschi Vieira. 14. ed. São Paulo: Hucitec, 2010c. Fontes, 2003

Estética da criação verbal. Tradução do russo de Paulo Bezerra. 4. ed. São Paulo: Martins

BAZERMAN, C. Escrita, gênero e interação social. Organização de Ângela Paiva Dionísio e Judith Chambliss Hoffnagel com equipe de tradução e adaptação sob a responsabilidade de Judith Chambliss Hoffnagel. São Paulo: Cortez, 2007.

BERNARDINO, R. A. S.; BESSA, J. C. R.; NASCIMENTO, I. A. de A.; CARVALHO, J. L. Q. A responsabilidade enunciativa na escrita do texto científico. Intersecções (Jundiaí), v. 8, p. 35-55, 2012. BESSA, J. C. R.; BERNARDINO, R. A. S.; NASCIMENTO, I. A. A. A citação na escrita acadêmicocientífica de estudantes universitários: da paráfrase ao plágio. Encontros de Vista, v. 9, p. 1-9, 2012. 
BESSA, J. C. R. Dialogismo e construção da voz autoral na escrita do texto científico de jovens pesquisadores. 2016, 385 f. Tese (Doutorado em Linguística e Língua Portuguesa) - Universidade Estadual Paulista "Júlio de Mesquita Filho", Faculdade de Ciências e Letras, Araraquara, 2016a.

O discurso citado na macroestrutura textual de artigos científicos de jovens pesquisadores. Ilha do Desterro, v. 69, n. 3, p. 45-61, Florianópolis, set/dez $2016 \mathrm{~b}$.

A citação na escrita acadêmico-científica: da reprodução fiel de palavras ao desafio da reformulação do dizer. Linguasagem, São Paulo, v. 18, s.p, 2011 a.

(Re)pensando a citação em textos acadêmico-científicos. Signum: Estudos da Linguagem, v. 14, p. 421, $2011 \mathrm{~b}$.

Referência ao discurso do outro: uma análise de problemas de relações de sentido entre discurso citado direto e discurso citante no gênero monográfico. 2007, 110 f. Dissertação (Mestrado em Estudos da linguagem) - Universidade Federal do Rio Grande do Norte, Natal, 2007.

BOCH, F; GROSSMANN, F. Referir-se ao discurso do outro: alguns elementos de comparação entre especialistas e principiantes. Scripta, v. 6, n.11, p. 97-108, 2002.

BOCH, F.; RINCK, F. Pour une approche énonciative de l'écrit scientifique. Lidil, n. 41, p. 5-14, 2010.

BOCH, F. Por que e como as coisas mudam ? Padronização e variação no campo do discurso científico. In: RINCK, F.; BOCH, F.; ASSIS, J. A. (Org.). Letramento e formação universitária: formar para a escrita e pela escrita. Campinas, SP : Mercado de Letras, 2015, p. 97-128.

Former les doctorants à l'écriture de la thèse en exploitant les études descriptives de l'écrit scientifique. Linguagem em (Dis)curso, Tubarão, SC, v. 13, n. 3, p. 543-568, set./dez. 2013.

BOURDIEU, P. Capital cultural, escuela y espacio social. Compilação e tradução de Isabel Jiménez. México: Siglo XXI Editores, 2005.

CHAROUX, O. M. G. Metodologia: processo de produção, registro e relato de conhecimento. São Paulo: DVS Editora, 2004.

CORACINI, M. J. Um fazer persuasivo: o discurso subjetivo da Ciência. 2. ed. Campinas: Pontes, 2007.

DEMO, P. O educador e a prática da pesquisa. Ribeirão Preto: Editora Alphabeto, 2009.

DINIZ, D.; TERRA, A. Plágio: palavras escondidas. Brasília: LetrasLivres; Rio de Janeiro: Editora Fiocruz, 2014.

ECO, U. Como se faz uma tese. Tradução de Gilson Cesar Cardoso de Souza. São Paulo: Editora Perspectiva, 2001.

GOERGEN, P. A internacionalização dos programas de pós-graduação. Revista Espaço Pedagógico, v. 19, n. 2, Passo Fundo, p. 247-257, jul./dez. 2012.

HYLAND, K. Stance and engagement: a modelo of interaction in academic discourse. Discourse studies, v. 7, n. 2, 173-192, 2005.

Academic attribution: citation and the construction of disciplinary knowledge. Applied Linguistics, 20(3), p. 341-367, 1999.

IVANIČ, R. Writing and identity: the discoursal construction of identity in academic writing. Amsterdam: John Benjamins Publishing Company, 1998.

LAVILLE, C.; DIONNE, J. A construção do saber: manual de metodologia da pesquisa em ciências humanas. Tradução de Heloísa Monteiro e Francisco Settineri. Porto Alegre: Artes Médicas, Sul Ltda.; Belo Horizonte: Editora UFMG, 1999.

MACHADO, A. M. N. A relação entre a autoria e a orientação no processo de elaboração de teses e dissertações. In: BIANCHETTI, L.; MACHADO, A. M. N. (Org.). A bússola do escrever: desafios e estratégias na orientação e escrita de teses e dissertações. 3. ed. São Paulo: Cortez, 2012, p. 60-81.

MEDEIROS, J. B. Redação científica: a prática de fichamentos, resumos, resenhas. 8. ed. São Paulo: Atlas, 2006.

MEDVIÉDEV, P. N. O método formal nos estudos literários: introdução crítica a uma poética sociológica. Tradução de Ekaterina Vólkova Américo e Sheila Camargo Grillo. São Paulo: Contexto, 2012.

MOTTA-ROTH, D.; HENDGES, G. R. Produção textual na universidade. São Paulo: Parábola Editorial, 2010.

PAIVA, V. L. M. de O. Avaliação da Pós-Graduação: publicações e projetos de pesquisa. São Paulo, 2015. Exposição em mesa-redonda realizada no XXX Encontro Nacional da ANPOLL - Produção, 
produtividade e produtivismo na área de Letras e Linguística hoje. São Paulo, 06, 07 e 08 de julho de 2015. Disponível em: <http://anpoll.org.br/eventos/enanpoll2015/wpcontent/uploads/2014/12/VeraFinal.pdf $>$. Acesso em 25 jul. 2015.

PECORARI, D. Repeated language in academic discourse: the case of Biology background statements. Nordic Journal of English Studies, v. 7, n. 3, p. 9-33, 2008.

PETRIĆ, B. Legitimate textual borrowing: Direct quotation in L2 student writing. Journal of Second Language Writing, 21, p. 102-117, 2012.

Rhetorical functions of citations in high and low-rated master's thesis. Journal of English for Academic Purposes, v. 6, n. 3, p. 238-253, 2007.

POLLET, M. C.; PIETTE, V. Citation, reformulation du discours d'autrui. Une clé pour enseigner l'écriture de recherche? Spirale, n. 29, p. 165-179, 2002.

PONZIO, A. A revolução bakhtiniana. Coordenação de tradução Valdemir Miotello. São Paulo: Contexto, 2009.

REUTER, Y. De quelques obstacles à l'écriture de recherche. Lidil, n. 17, p. 11-23, 1998.

RINCK, F; MANSOUR, L. Littératie à l'ère du numérique: le copier-coller chez les étudiants. Linguagem em (Dis)curso, Tubarão, v. 13, n. 3, p. 613-637, set./dez. 2013.

RINCK, F. Styles d'auteur et singularité des textes - approche stylométrique du genre de l'article en linguistique. Pratiques, n 135/136, p.119-136, dez. 2007.

SANCHEZ, D. Aplicabilidad de la tipología de funciones retóricas de las citas al género de la memoria de máster en un contexto transcultural de enseñanza universitaria. Rev. Signos, v. 46, n. 81, p. 82-104, 2013.

SANTOS, A. R. dos. Metodologia científica: a construção do conhecimento. 7. ed. Rio de Janeiro: Lamparina Editora, 2007.

SANTOS, J. A.; FILHO, D. P. Metodologia científica. São Paulo: Futura, 1998.

SILVA, A. O. A sua revista tem Qualis? Mediações, v. 14, n.1, p. 117-124, Jan/Jun. 2009.

STREET, B. Dimensões "escondidas" na escrita de artigos acadêmicos. Perspectiva, v. 8, n. 2, p. 541 567,2010

SWALES, J. Genre analysis: English in academic and research settings. Cambridge: CUP, 1990.

THOMPSON, P. Loooking at citations: using corpora in english for academic purposes. Language Learning \& Technology, v. 5, n. 3, 91-105, 2001.

VILAÇA, M. M.; PEDERNEIRA, I. L. Assim é, se lhe parece: “em-cena-ação" científica num país fictício em tempos de publicar ou perecer... mas bem que poderia ser no Brasil. Interface: comunicação, saúde, educação, v.17, n.44, p.235-41, jan./mar. 2013.

VOLOCHÍNOV, V. N. A construção da enunciação e outros ensaios. Organização, tradução e notas de João Wanderley Geraldi. São Carlos: Pedro \& João Editores, 2013.

WHITE, H. D. Citation analysis and discourse analysis revisited. Applied Linguistics, v. 25, n. 1, 89-116, 2004.

\section{Recebido em: 13/10/16. Aprovado em: 09/05/17.}

Title: Value dimension in discourses about the use of citation in the writing of academic texts Autor: José Cezinaldo Rocha Bessa

Abstract: Based on the dialogical conception of Bakhtin's Circle language, in which ideological values constitute human language, and in researches on scientific writing, especially in enunciative and discursive perspective, this text presents a study about the value dimension that underlies the discourse on the use of citations in communicative practices of the academic-scientific sphere. From an interpretative nature and adopting a qualitative approach, the research examines textbooks of scientific work methodology and scientific writing that circulate in the academic universe and the Brazilian publishing market. The study indicates the discourses materialized in the methodology manuals of scientific work and scientific writing analyzed disseminate values that contribute to a framework of paradoxical demands that can confuse and mislead students in research training instead of effectively contribute to a creative communicative practice, appropriate and relevant.

Keywords: Scientific text. Young researcher. Discourse. Citation. Value dimension. 
Título: La dimensión valorativa en discursos sobre el uso de citas en la escrita de textos científicos

Autor: José Cezinaldo Rocha Bessa

Resumen: Fundamentado en la concepción dialógica del lenguaje del Círculo de Bakhtin, segundo la cual los valores ideológicos constituyen el lenguaje humano, y en trabajos sobre escrita científica, sobretodo en perspectiva enunciativa y discursiva, este texto presenta un estudio sobre la dimensión valorativa que se amplía al discurso sobre el uso de citas en las prácticas comunicativas de la esfera académico-científica. De naturaleza interpretativa y asumiendo un abordaje cualitativo, el trabajo realiza un examen de manuales de metodología del trabajo científico y de redacción científica que circulan en el universo académico y en el mercado editorial brasileño. El estudio hecho indica que los discursos materializados en los manuales de metodología del trabajo científico y de redacción científica analizados diseminan valores que colaboran para un cuadro de exigencias paradoxales, las que pode mucho más confundir y desorientar el estudiante en entrenamiento en pesquisa que contribuir efectivamente para una práctica comunicativa científica creativa, adecuada y relevante.

Palabras-clave: Texto científico. Joven investigador. Discurso. Cita. Dimensión valorativa

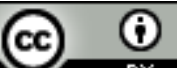

Este texto está licenciado com uma Licença Creative Commons Atribuição 4.0 Internacional. 